\title{
Experimental testing and simulations of an autonomous, self-propulsion and self-measuring tanker ship model
}

\section{Abstract}

Improving the energy efficiency of ships has generated significant research interest due to the need to reduce operational costs and mitigate negative environmental impacts. Numerous hydrodynamic energy saving technologies have been proposed. Their overall performance needs to be assessed prior to implementation. A new approach to this evaluation is investigated at model scale which applies an approach comparable to that applied for the performance monitoring of a full scale ship. That is long duration testing that measures power consumption for given environmental and ship operating conditions and can use statistical analysis of the resultant large amount of data to identify performance gains. As a demonstration of the approach, an autonomous, self-propelled and self-measuring free running ship model of an Ice Class tanker is developed. A series of lake based and towing tank tests experiments have been conducted which included bollard pull, shaft efficiency, naked-hull, self-propulsion, and manoeuvrability tests. These investigated the efficiency improvement resulting from changing the ship operational trim and testing different bow designs. An associated mathematical model for the time domain simulation of the autonomous ship model provides an effective tool for data analysis. It has been demonstrated that the use of a suitably instrumented selfpropelled autonomous ship model can provide long duration tests that incorporates the influence of varying environmental conditions and thereby identify marginal gains in ship energy efficiency.

Keywords: Ship energy efficiency, Tanker ship, Model testing, Simulink, Autonomous

\section{Introduction}

Model testing is considered as the standard procedure of predicting ship resistance, powering, manoeuvrability and sea-keeping during the design stage enabling designers to predict the required full-scale ship installed power (Molland et al., 2011). Ship model experiments can also be used to provide deeper insight into the ship power requirements throughout a whole voyage including power margin due to environmental conditions such as wind and waves (ITTC, 2017) which is an essential element for studying different power systems such as hybrid electric systems and alternative power sources. Similarly, model testing allows the influence of any modifications to the ship hull or its operating conditions to be studied. However, commercial model testing is expensive, time-consuming and it suffers from scale effects. Advocates of computational fluid dynamics say that an approach based on numerical simulation offers a flexible environment to build, test, and analyse ship system performance (Neilson and Tarbet, 1997). This allows the simulation environment user to optimize, tune, or test possible changes in the ship design parameters, surrounding environment conditions, investigate different power sources or energy management strategies without conducting experiments each time. Unfortunately the benefits of CFD reduce rapidly once realistic, dynamic conditions are considered as high resolution meshes with small time steps are required which requires massive computational power just

\footnotetext{
* Corresponding author

Email address: ab2e12@alumni.soton.ac.uk (Ameen M. Bassam )
} 
to consider a single design condition. Ship model experimental work is still the most essential and reliable method for dynamic testing and validation (Bertram, 2012) and ship dynamic performance is more quickly assessed.

A major focus for the shipping industry is how to improve the energy efficiency of ships in order to: limit the negative environmental impact of sea transport, reduce fuel costs and therefore enhance ship profitability. As a result, technologies, measures, and mechanisms have been proposed and adopted including the introduction of the Energy Efficiency Design Index (EEDI) and the Ship Energy Efficiency Management Plan (SEEMP) by the International Maritime Organization (IMO) aiming to reduce ships fuel consumption and greenhouse gas (GHG) emissions and to improve shipping energy efficiency (Smith et al., 2014 Rehmatulla et al. 2017). The EEDI is mandated for new ships and it requires a minimum environmental cost in terms of $\mathrm{CO}_{2}$ emissions divided by transport work. Moreover, the EEDI as a standard aims to reduce GHG emissions using technical and design-based solutions such as optimizing hull dimensions, engines and propellers or using unconventional fuels and renewable energy sources. Meanwhile, the SEEMP is formulated for all ships and it targets the operational measures and practices such as weather routing and trim/draft optimization (Rehmatulla et al., 2017, Bazari and Longva, 2011).

Since there are various EEDI and SEEMP measures and technologies, selecting the optimal solution to be implemented for improving energy efficiency of a specific ship is a challenging issue. This is partially due to the lack of technical information about the overall implementation of such measures onboard ships and the fact that available data from IMO is limited and anonymous (Rehmatulla et al., 2017). In addition to technical risks, there is a business risk associated with investments in new energy efficiency technologies and its payback periods, life cycle and hidden costs (Rehmatulla and Smith, 2015).

Therefore, it is of significant importance to properly evaluate the effectiveness of ship energy efficiency suggested measures before its implementation. Also, EEDI calculation and verification are required for legislation by the IMO at the design stage through model testing which considers as the most important element of EEDI preliminary verification (Resolution MEPC.254(67), 2014). For example, model testing and simulation were used to study the influence of employing wavefoils on resistance and motion reduction of tanker ships in regular and irregular waves (Bøckmann and Steen, 2016). Also, to study ship motion control and guidance, an autonomous surface vehicle model of the tanker ship Esso Osaka has been developed for manoeuvrability testing (Moreira and Soares, 2011). Another autonomous self-propelled ship model of a tanker ship was also developed for manoeuvrability studies and control (Perera et al., 2012). For container ships, a study of ship motion control has used a free running ship model in experimental study where a simulation model has been built as well (Zheng et al., 2018). Moreover, a self-propelled unmanned free running model of a twin screw twin rudder ship has been developed and tested for manoeuvrability studies in (Coraddu et al., 2013) and the experimental results were also used to obtain a simplified manoeuvrability simulator on a model scale.

The aim of this study is to investigate the development of system that can acquire ship performance data, at low cost and in a range of suitably scaled wave conditions at model scale. Such a system requires a suitable body of water, usually an inland lake, and ideally a self-propelled, instrumented model that can acquire data automatically over relatively long periods of time ( 8 hours + ). The targeted efficiency improvement measures are changing the ship operational conditions of trim and testing different bow designs for different loading conditions (Anderlini et al., 2013). The small changes in powering requirements resulted from changing the trim and bow design can be also identified statistically based on the experimental data. In order to perform this investigation, an autonomous, self-propulsion and self-measuring tanker ship model has been built and operated in towing tanks and natural open water body such as lakes to limit the cost of such investigations. The ship model is then mathematically modelled to develop a model simulator with the help of MATLAB/Simulink environment using its Simscape Power Systems (SPS) toolbox (SPS, 2018) to be as a complementary to model testing allowing the study of changing the operational conditions without performing model testing each time which saves time, effort and cost (Coraddu et al. 2013). The experimental results are then used to validate the model simulator.

The main focus of this work is on the introduction of the autonomous tanker ship model and related experimental results in addition to introducing and validating the developed simulator. The paper is organized as follows. Section 2 introduces the examined ship model and its main systems. Section 3 describes 
the conducted experimental work using the ship model showing some example results. Section 4 illustrates the ship model simulation implementation and validation. Finally, the conclusions and further work are presented in Sections 5 and 6 .

\section{Ship model description}

According to the last IMO GHG study, oil tankers dominates the total shipping fuel consumption with container ships and bulk carriers. This fuel consumption dominates the ship operational cost where heavy fuel oil is the dominant fuel type which deteriorates the environmental performance of shipping (Smith et al. 2014; Argyros et al. 2014). Consequently, a 1/60 scale model tanker shown in Figure 1 has been developed at the University of Southampton to study ship energy efficiency improvement using model testing and its main particulars are shown in Table 1. Next, the main components of the model will be briefly described.

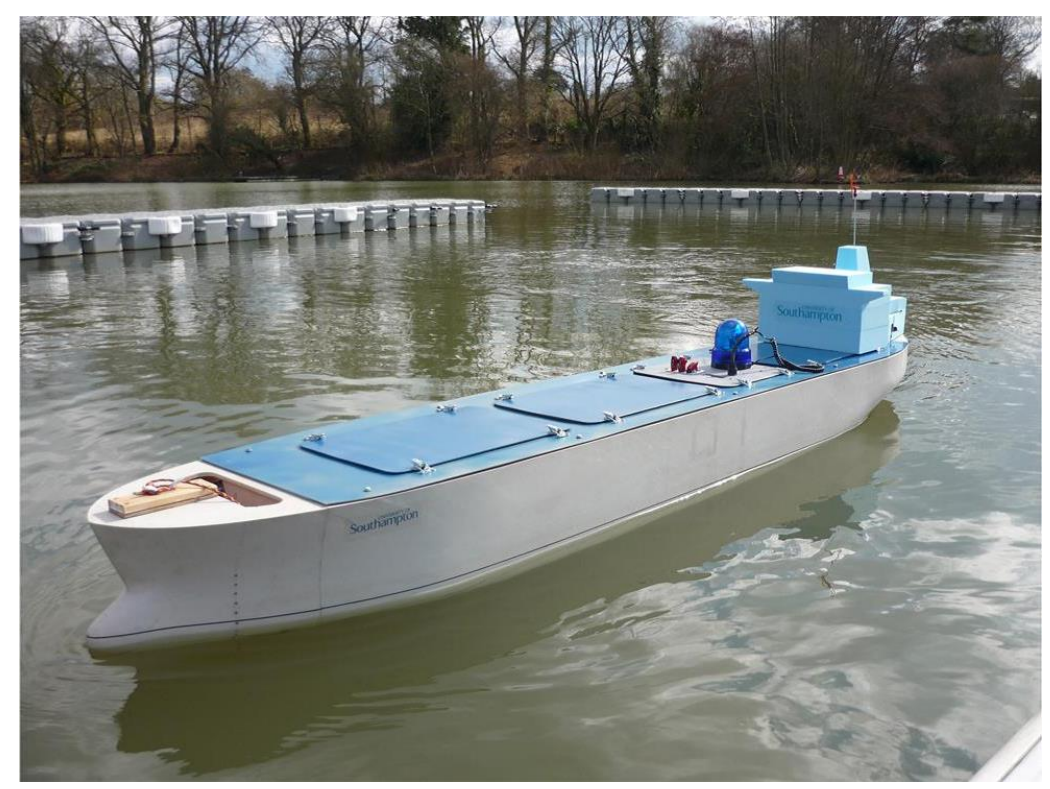

Figure 1: Tanker ship model in ballast condition

Table 1: Principal particulars of the examined Ice Class vessel

\begin{tabular}{llll}
\hline Parameter & unit & Ship & Model \\
\hline Length overall & $\mathrm{m}$ & 183.88 & 3.06 \\
Length between perpendiculars & $\mathrm{m}$ & 174 & 2.9 \\
Breadth & $\mathrm{m}$ & 32.2 & 0.54 \\
Height & $\mathrm{m}$ & 18.8 & 0.31 \\
Draft (Full load) & $\mathrm{m}$ & 11.02 & 0.1837 \\
Draft (Ballast load) & $\mathrm{m}$ & 6.91 & 0.1152 \\
Service speed (Full load) & $\mathrm{m} / \mathrm{s}$ & 7.974 & 1.029 \\
Service speed (Ballast load) & $\mathrm{m} / \mathrm{s}$ & 6.687 & 0.863 \\
Displacement (Full load) & tonnes & 49969 & 0.2257 \\
Displacement (Ballast load) & tonnes & 29773 & 0.1345 \\
Block coefficient (Full load) & & 0.7994 & 0.7994 \\
Block coefficient (Ballast load) & & 0.7596 & 0.7596 \\
\hline
\end{tabular}




\subsection{Autonomy \& Control}

For the model to be able to perform its required missions with high repeatability without the need for continuous human control and expensive ocean basins, the ship model is built as autonomous. Moreover, autonomous systems help to achieve more complex missions with longer duration and range in open-water uncontrollable environments which allows the collection of large amounts of data with higher measurement accuracy and cost efficiency than using towing tanks (Dunbabin et al., 2009). The control and autonomy of the developed autonomous ship model has been written using the Robot Operating System (ROS) (ROS.org, 2018) in a hierarchical structure as shown in Figure 2. The hardware interface layer consists of software drivers developed to interact with sensors and actuators. This level is responsible for reading the signals of different sensors of the ship model, processing these signals, and then transferring them to other levels.

The controller layer contains the speed and heading controllers. The heading controller code calculates the required rudder angle as a function of the difference between the compass current heading and the required heading demand. The required heading demand is provided from the mission executive layer which contains the codes of the required missions, tests and manoeuvres (e.g. straight run, circle, zig-zag, etc.) to be executed. Then, the rudder angle demand is calculated using a standard PID controller due to its robustness, simplicity, and ease of use and tuning (Moreira et al., 2007).

The safety system monitors all the hardware communications and continuously compares its current values with the limit values to stop the system in case of the presence of any error. It is also possible to control the ship model manually with ashore computer by sending direct commands in ROS to prevent any problems such as collisions.

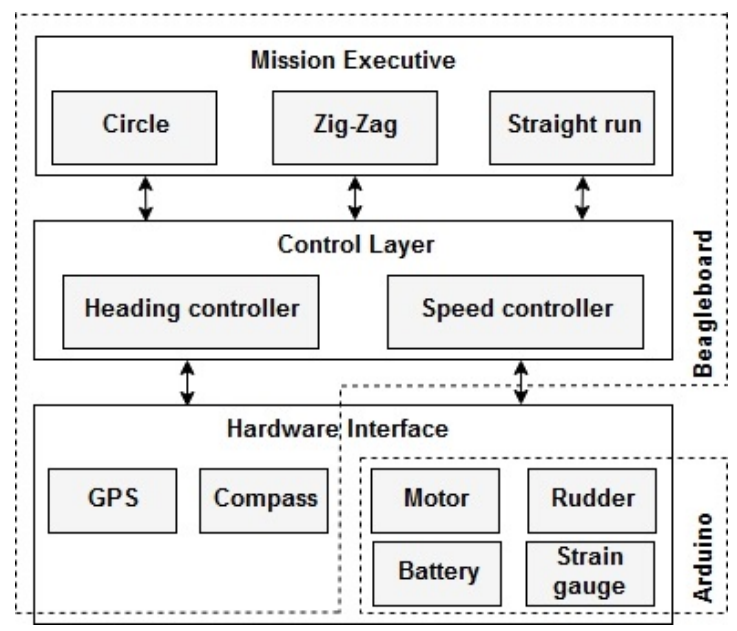

Figure 2: Overview of the tanker ship control system architecture

The central processing unit of the built ship model is a Beagleboard $x M$ with 512 MB of RAM and 1 GHz Cortex-A8 processor. The Beagleboard $x M$ was selected to take advantage of its tiny 3.25" by 3.25" footprint, the ability of using storage media, 10/100 Ethernet, and 4 USB 2.0 ports which allows all the components to be connected to the BeagleBoard directly (BeagleBoard, 2018). These components include the GlobalSat $B U$-353S4 GPS unit with USB interface and a $1 \mathrm{~Hz}$ sampling rate which is responsible for providing geolocation and time information of the ship model during lake testing. The master Arduino is also connected via a USB port and it reads the collected sensors data from the motor, rudder, battery, strain gauge, etc. as shown in Figure 2. The master Arduino uses a Pro Mini (5 V/16 Mhz) microcontroller type because of its suitable speed and price.

\subsection{Mechanical system}

The main components of the mechanical system power train include the electric motor, shafting system, thrust block, and propeller. This power train is supported by linear bearings to be able to slide with less 
friction losses allowing a longitudinal movement and free-floating for the entire system as shown in Figure 3. By applying this design concept, the developed propeller thrust is transferred solely by the thrust block which minimizes losses and ensures accurate measurements of the thrust through the strain gauge. The power train unit itself was made of aluminium easyfix tube system chosen for its light weight and ease of use.

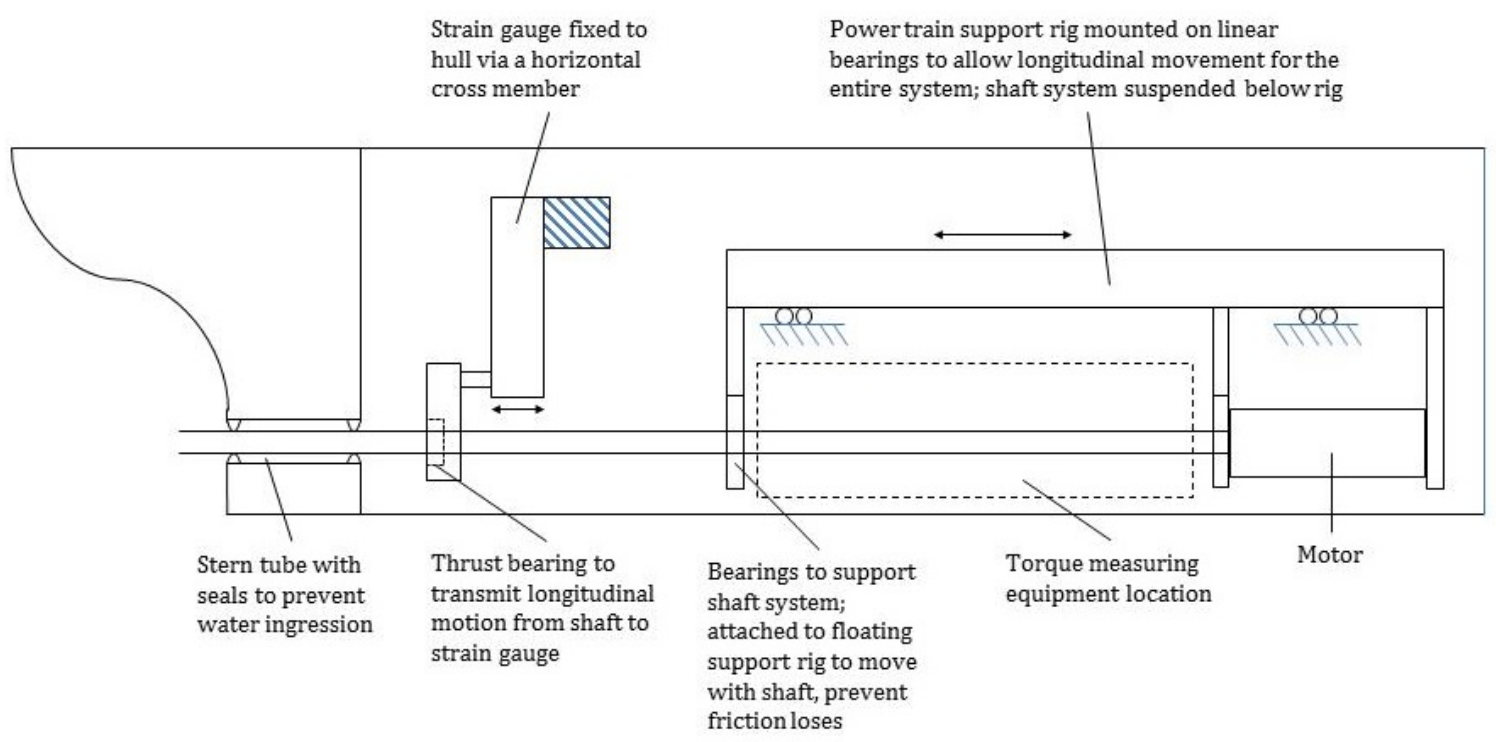

Figure 3: Power train assembly diagram (Anderlini et al. 2013

By scaling down the resistance and power requirements of the full-scale ship, a suitable motor and propeller were properly selected for the ship model. The operating torque and thrust requirements were met by a Maxon $12 \mathrm{~V}$ DC motor with a maximum efficiency of $88 \%$ coupled to a $3.5: 1$ reduction gearbox. This motor is controlled by a SyRen50 Pulse Width Modulation (PWM) motor controller which controls the motor applied voltage as a function of the motor demand value. The motor controller is also responsible for measuring the motor rotational speed, voltage, and current. The measured motor current is then converted to a motor torque using the motor torque constant of $16.4 \mathrm{mNm} / \mathrm{amp}$ supplied by the manufacturer (Maxon, 2018). Next, the motor torque is used to estimate the propeller torque as a function of the shaft efficiency. The motor drives a 4 blades fixed pitch propeller which corresponds exactly to the model-ship scale ratio.

Based on the power requirements of the electric motor and other mechanical and electronic devices, 4 lead-acid batteries were decided to be used as a $12 \mathrm{~V}$ power source with a capacity of 60 amp-hour per battery which could supply the ship model for at least 8-hours. Lead-acid batteries were chosen for its relatively cheaper price and its weight which would be useful as ballast for the ship model. To step-down the battery voltage from the $12 \mathrm{~V}$ level to power microcontrollers, a DC-DC converter with an efficiency of $93 \%$ was used.

In order to assess the performance of the built model in terms of the ability to perform autonomous missions measuring its powering and maneuvering characteristics, a set of different tests in different environments were performed as discussed in the following section.

\section{Ship model testing \& evaluation}

The actual performance of the tanker ship model has been evaluated through different test environments including laboratory and towing tanks and open-water environments. This section covers the conducted set of testing using the ship model which included bollard pull, shaft efficiency, naked-hull, self-propulsion and different manoeuvrability tests. 


\subsection{Towing tank testing}

This experimental activity was carried out within the QinetiQ's towing tank in UK which is $270 \mathrm{~m}$ long, $12.2 \mathrm{~m}$ wide, and $5.4 \mathrm{~m}$ deep. Towing tank tests included bollard pull tests for the calibration of the model's thrust sensor for both full load and ballast conditions. As recommended for bollard pull test by the International Towing Tank Conference (ITTC), the hull was affixed to the regularly checked carriage tow post to measure the thrust values $\left(\mathrm{T}_{\mathrm{C}}\right)$ at different propeller speeds and zero ship model speed and equated it with the readings produced by the load cell onboard the ship model $\left(\mathrm{M}_{\mathrm{raw}}\right)$ as shown in Figure $4 \mathrm{a}$ to estimate the calibration coefficients and calibrate the model thrust readings for further tests.

The measured motor current during the bollard pull tests were then compared against the drained motor current while detaching the propeller at various rotational speed in an attempt to find the shaft efficiency which stayed roughly constant at different speeds and the average shaft efficiency was found to be about $71 \%$ as shown in Figure $4 \mathrm{~b}$. As it could be expected, a quite lower shaft efficiency was obtained at model scale due to the higher shaft rotational speed compared to the full-scale ship. The shaft efficiency was then used to estimate the propeller torque as a function of the motor torque but, for future work, a torque dynamometer should be used instead for higher accuracy.

Naked-hull tests were also performed to determine the model naked-hull resistance at different loading conditions of full load (FL) and ballast load (BL) at the model default trim (DT) as well as different trims (T1 and T2) as an energy efficiency measure as shown in Figure 4c. The considered different values of trim conditions were privately supplied by the shipping company for realistic loading conditions and it all fulfil different stability and structure criteria and regulations.

The measured model drag from the tank carriage dynamometer was used to calculate the ship model total resistance coefficient $\left(C_{\mathrm{T}}\right)$ as a function of the water density $(\rho)$, model wetted surface area $(S)$, and model speed $(V)$ using Equation 1 .

$$
C_{\mathrm{T}}=\frac{D r a g}{0.5 \rho S V^{2}}
$$

The model total resistance can be broken down into skin frictional resistance and residual resistance according to Froude's traditional approach (Molland et al., 2011). Accordingly, the total resistance coefficient $\left(C_{\mathrm{T}}\right)$ was used to calculate the residual resistance coefficient $C_{\mathrm{R}}$ as a function of the frictional resistance coefficient $C_{\mathrm{F}}$ according to Equation 2. Meanwhile, $C_{\mathrm{F}}$ can be calculated according to the ITTC formula (Equation 3) as a function of the model Reynolds number $(R e)$ calculated according to Equation 4 as a function of the model length between perpendiculars $\left(L_{P P}\right)$ and water kinematic viscosity $(\nu)$.

$$
\begin{gathered}
C_{\mathrm{T}}=C_{\mathrm{R}}+C_{\mathrm{F}} \\
C_{\mathrm{F}}=\frac{0.075}{(\log R e-2)^{2}} \\
R e=\frac{V L_{P P}}{\nu}
\end{gathered}
$$

The traditional approach of Froude was chosen over the form factor approach recommended by the ITTC because the form factor approach requires testing the ship model with relatively low Froude number (Molland et al. 2011), however the towing tank carriage dynamometer doesn't provide precise drag readings at very low Froude numbers. Afterward, the model total resistance was scaled up to calculate the ship total resistance $\left(R_{\mathrm{Ts}}\right)$ and effective power $\left(P_{\mathrm{E}}\right)$ at different ship speed $\left(V_{\mathrm{s}}\right)$ and loading conditions according to Equation 5 as shown in Figure $4 \mathrm{e}$. The ship delivered power can be then calculated as a function of $\left(P_{\mathrm{E}}\right)$, quasi-propulsive coefficient, and the model-ship correlation factor.

$$
P_{\mathrm{E}}=R_{\mathrm{Ts}} V_{\mathrm{s}}
$$

Similarly to the naked hull tests, self-propulsion tests of the ship model at towing tank were performed with different trim conditions in order to find the model self-propulsion point, where the model resistance is 
equal to the propeller thrust, and to evaluate the propulsion factors of wake fraction and thrust deduction as a function of the model resistance $(\mathrm{R})$, thrust $(\mathrm{T})$ and speed as shown in Figure $4 \mathrm{f}$. The ship self-propulsion point can also be evaluated from the self-propulsion test by taking into account the skin friction correction force resulting from the difference in skin friction coefficients between the model and the full scale ship according to (ITTC, 2008b). The correction force value was then offset on the diagram as shown in Figure $4 f$ to obtain the ship self-propulsion point.

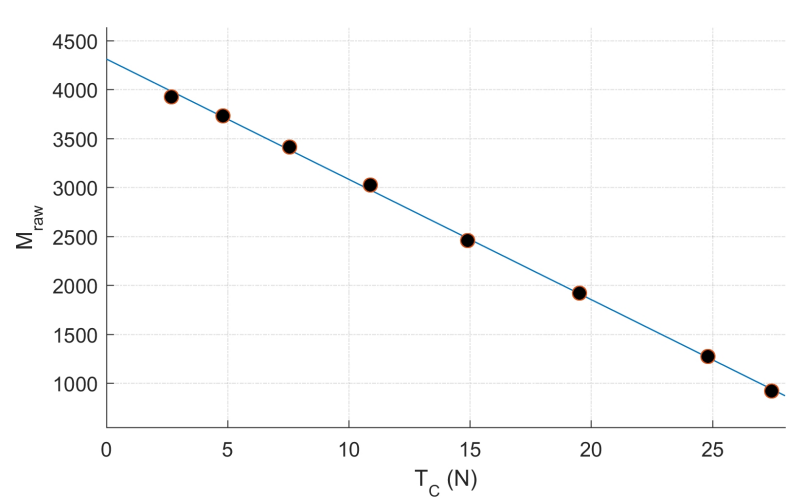

(a) Thrust calibration for the $\mathrm{FL}_{\mathrm{DT}}$ condition

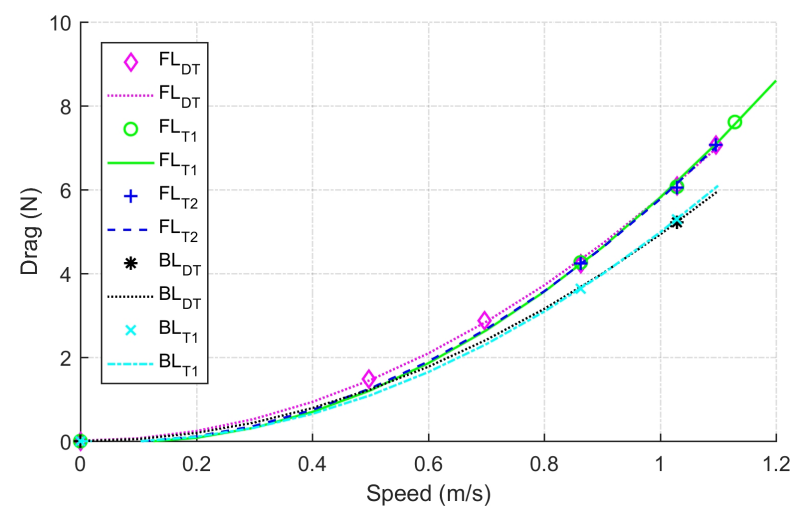

(c) Experimental results for model naked-hull tests

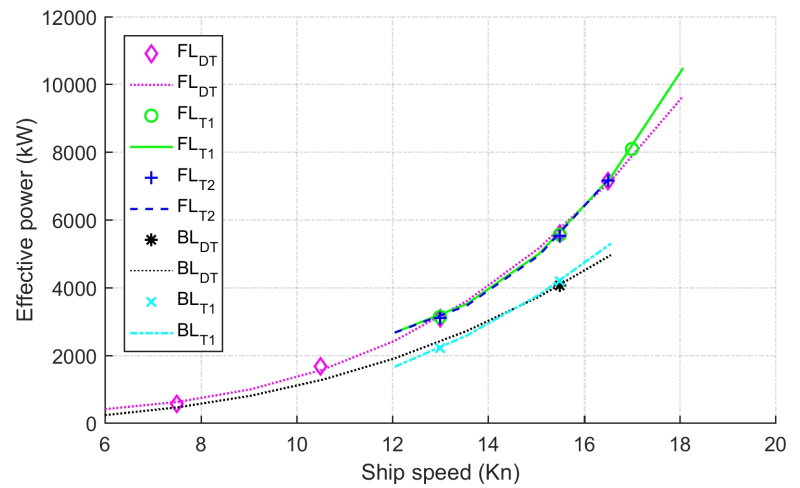

(e) Ship effective power requirements for different loading conditions

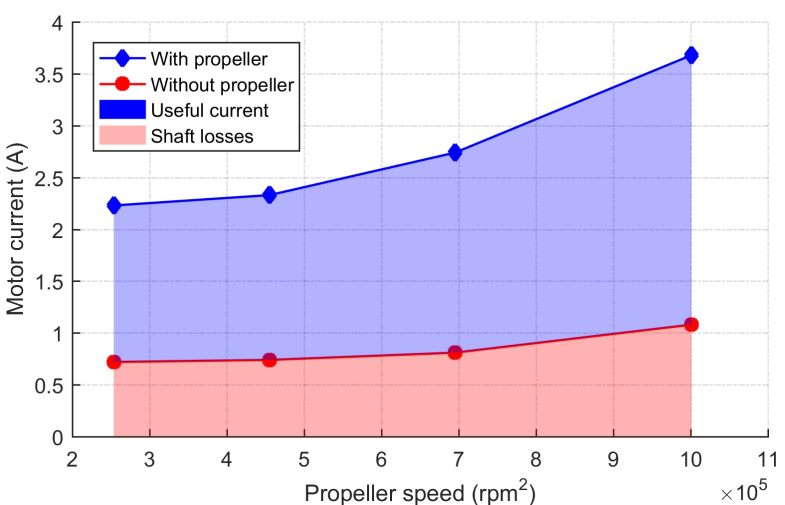

(b) Motor current with and without the propeller

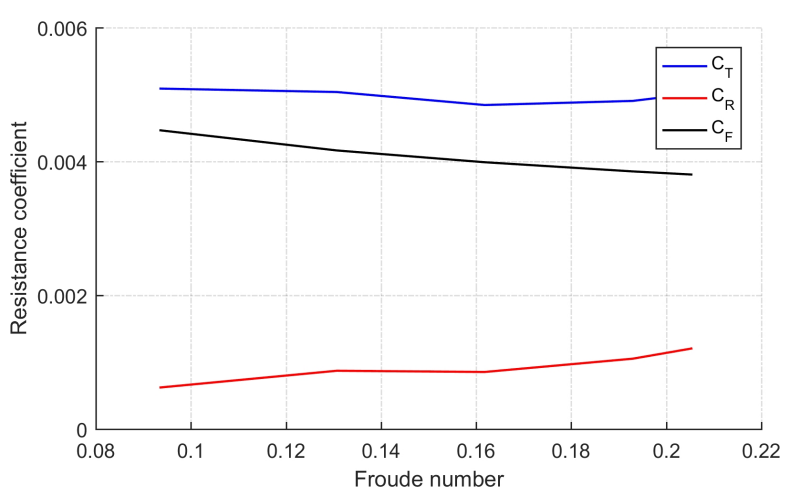

(d) Model resistance coefficients for the $\mathrm{FL}_{\mathrm{DT}}$ condition

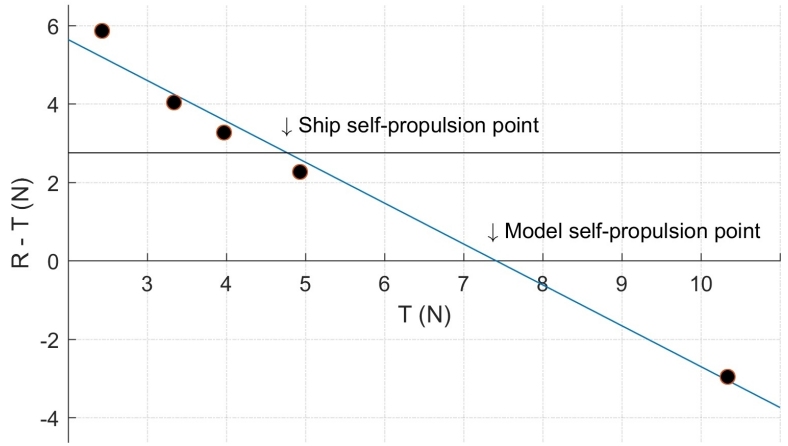

(f) Self-propulsion test results for the $\mathrm{FL}_{\mathrm{DT}}$ condition

Figure 4: Example of towing tank experimental results 
Since the ship has lighter load and less wetted surface area and draft in ballast condition, less resistance power requirements are to be expected compared to full load condition. Comparing Figures $4 \mathrm{c}$ and $4 \mathrm{e}$ shows that there is a noticeable difference between FL and BL resistance and power requirements as anticipated. Also, there is a slight improvement in resistance and power requirements for the $\mathrm{FL}_{\mathrm{T} 1}$ over the $\mathrm{FL}_{\mathrm{DT}}$ condition by $0.6 \%$ at the service speed of about $15 \mathrm{kn}$. Meanwhile, for ballast condition, the power requirement is lower at the $\mathrm{BL}_{\mathrm{DT}}$ condition than the alternative trim $\mathrm{BL}_{\mathrm{T} 1}$ by $2.9 \%$ at the same speed as shown in Figures $4 \mathrm{c}$ and $4 \mathrm{e}$

Moreover, at the $\mathrm{FL}_{\mathrm{DT}}$ condition, the thrust which corresponds to the self-propulsion point of the model was $7.4 \mathrm{~N}$ as shown in Figure $4 \mathrm{f}$ which was then used with the model resistance at the same speed to calculate the model's thrust deduction which was found to be 0.17. According to this point of self-propulsion, the propeller speed and diameter were used with the model speed to calculate the model wake fraction and it was found to be 0.45 . For the full-scale ship, a skin friction correction force of $2.75 \mathrm{~N}$ was calculated and offset as can be observed in Figure $4 \mathrm{f}$ to obtain the ship self-propulsion point at the $\mathrm{FL}_{\mathrm{DT}}$ condition. Eventually, the model self-propulsion point was considered to be a good starting point for the lake testing by providing a propeller speed range around the self-propulsion point to be tested as will described in the following section.

\subsection{Lake testing}

The second phase of testing was performed on an open-water environment which is available and free to use removing the need for expensive towing tanks. The experimental testing were carried out in Timsbury Lake located about $5 \mathrm{kms}$ north of Romsey, Hampshire and it has harbor area with 19 jetties, turning basins, critical bends and buoyed channels as shown in Figure 5 which makes it an ideal location for training and experiments. The main purpose of lake testing was to assess the effectiveness of the built ship model as a testing platform capable of performing autonomous tasks, measuring its powering, sea-keeping, manoeuvring and stability characteristics and communicating with the shore successfully in an open-water environment which is uncontrollable and unpredictable. Also, the ship model was used to test different bow designs as an EEDI measure to improve ship efficiency in waves which was part of another individual project at the University of Southampton (Cooke, 2013). Lake testing included straight run, circle and zig-zag tests at only the full load condition at the default trim using different bows because of time constraints and there were no significant improvement due to changing trim as shown in Figures $4 \mathrm{c}$ and $4 \mathrm{e}$ A bollard pull test was also repeated before conducting the lake experiments to confirm the system accuracy.

In order to cover a large operational range of the model for different tests, three propeller rotational speeds were tested corresponding to the predicted model self-propulsion point. These propeller speeds were below, approximately equal and higher than the model self-propulsion point of 750, 1000, and 1250 revolution per minute (rpm) respectively. Prior to every test, the desired propeller rpm was accurately set as a function of the motor demand and gearbox ratio in the required mission code located in the mission executive layer. Moreover, by exploiting the ship model original position before every run and satellites signals, the GPS calculated the ship model speed, its latitude and longitude, and its $\mathrm{x}$ - and $\mathrm{y}$ - coordinates versus time during lake testing. Also, multiple runs of each test were performed in an attempt to account for the changing environment conditions and to increase the amount of available experimental data. An example of the data obtained from the straight line, zig-zag and turning circle tests are shown in Figure 6 .

Straight line testing was carried out close to the centre-line of the lake with an approximate length of $80 \mathrm{~m}$ where the main aim of this test was to estimate the model resistance and power consumption using different bows in waves to assess any efficiency improvement as shown in Figure6a. It can be observed that the first alternative bow results in less power consumption by $18.7 \%$ and $28 \%$ at the service speed compared to the normal bow and the second alternative bow respectively. For confidentiality reasons, further details about different bow designs and geometry are not disclosed in this paper. However, these results should be treated with caution because it is subjected to the employed sensors accuracy and reliability. Therefore, a statistical analysis was performed on a sample of the straight line lake testing to show the measurement variation from their mean in terms of standard deviation (SD) as shown in Table 2

Because of the occasional loss of a satellite fix and the low sampling rate of the GPS system of 1 $\mathrm{Hz}$, model speed measurement had high SD as shown in Table 2 Further work therefore is planned to 


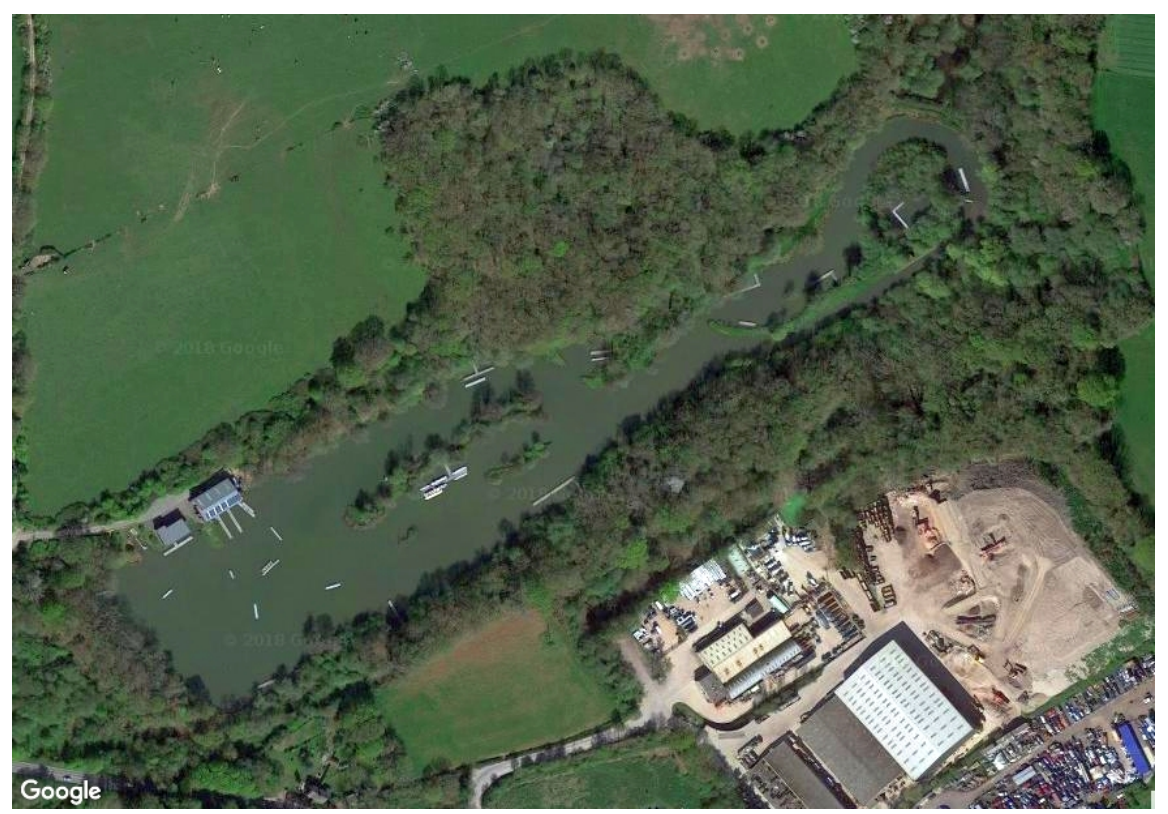

Figure 5: Satellite view of Timsbury Lake

Table 2: A sample of straight line lake testing showing mean and standard deviation

\begin{tabular}{|l|ll|ll|ll|ll|l|l|}
\hline & \multicolumn{2}{|l|}{ Model speed } & \multicolumn{2}{l|}{ Propeller speed } & \multicolumn{2}{l|}{ Propeller thrust } & \multicolumn{2}{l|}{ Motor current } & \multicolumn{2}{l|}{ Motor voltage } \\
\hline & $\begin{array}{l}\text { Mean } \\
(\mathrm{m} / \mathrm{s})\end{array}$ & $\begin{array}{l}\text { SD } \\
(\%)\end{array}$ & $\begin{array}{l}\text { Mean } \\
(\mathrm{rpm})\end{array}$ & $\begin{array}{l}\text { SD } \\
(\%)\end{array}$ & $\begin{array}{l}\text { Mean } \\
(\mathrm{N})\end{array}$ & $\begin{array}{l}\text { SD } \\
(\%)\end{array}$ & $\begin{array}{l}\text { SD } \\
(\mathrm{A})\end{array}$ & $\begin{array}{l}\text { Mean } \\
(\%)\end{array}$ & $\begin{array}{l}\text { SD } \\
(\%)\end{array}$ \\
\hline Run 1 & 0.64 & 24.53 & 750.42 & 1.09 & 5.12 & 18.69 & 2.14 & 2.33 & 4.56 & 1.08 \\
Run 2 & 0.74 & 25.56 & 1000.51 & 0.93 & 8.38 & 9.38 & 2.22 & 4.11 & 6.15 & 1.17 \\
Run 3 & 1.07 & 15.64 & 1250.09 & 0.94 & 13.05 & 11.6 & 3.23 & 6.15 & 8.04 & 1.05 \\
\hline
\end{tabular}

install another GPS with a faster sampling rate for future testing. On the other hand, propeller speed measurement had low SD of about $1 \%$ and its mean was very close to the targeted value of 750,1000 , and $1250 \mathrm{rpm}$ owing to the used high precision optical encoder. Thrust measurement was less reliable than the propeller speed measurement due to the strain gauge sensitivity to the model physical vibration caused by the motor, the propeller, or its shaft. Therefore, an optical sensor which requires no physical contact should be used to measure the thrust. Regarding the motor current and voltage used to calculate the model power requirements, it showed good results with low SD which means less variability and high stability of the measurements (Tilman et al., 1998).

Standard maneuvering tests required by the IMO were also conducted using the tanker model such as turning circle and zig-zag tests where the model was free to move in the 6 degrees of freedom and the propeller run at a constant revolution speed throughout the tests as suggested by the IMO (ITTC, 2008a). Although it is also recommended by the IMO to test the free running ship model manoeuvrability in a calm water condition (ITTC, 2008a), proving the capability of the built ship model was the main focus of the lake testing. Consequently, due to inclement environmental conditions during the model testing, the model motion during manoeuvres was affected as shown in Figure 6c with an increased margin of error was to be expected. In addition, the recorded GPS readings were not always accurate which affected the model position data. For these reasons, manoeuvring details such as advance, transfer, and period haven't been estimated. However, despite the uncertainty related to environmental condition and torque measurements and facing issues related to the model hardware (e.g. GPS) expected for a novel system, the built ship model has proved its capability and flexibility as a testing platform and a large amount of useful experimental data 


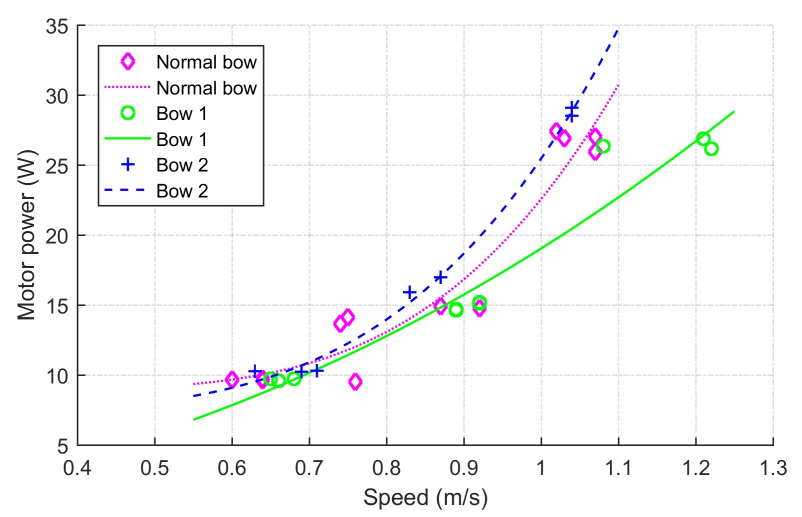

(a) Model power requirements using different bows

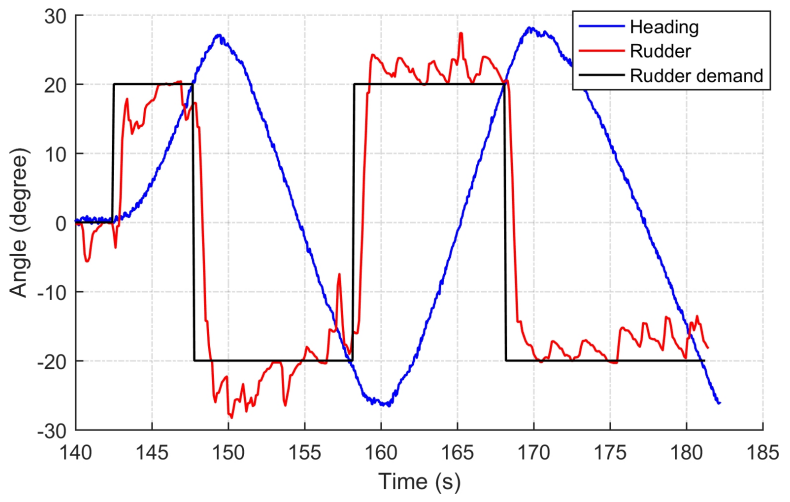

(b) Heading, rudder and rudder demand angles during a zig-zag test

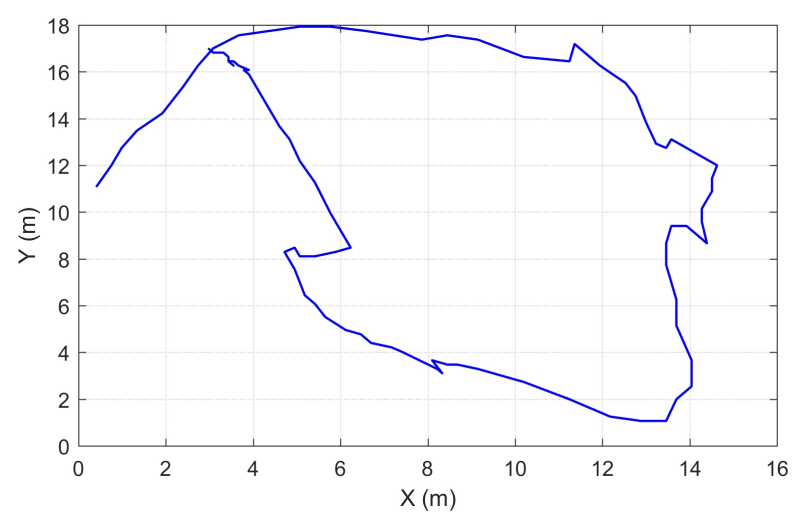

(c) Turning circle trajectory

Figure 6: Example of towing tank experimental results

from towing tank and lake testing was collected. Nevertheless, the approach of using long acquisition periods to help reduce environmental uncertainty has been demonstrated further work is required to enhance the accuracy of the individual sensors. For example with trim by using multiple inertial sensors as has been applied by (Bennett et al. 2014) to measure the hydroelastic behaviour of a flexible ship model.

In order to study and optimize some operational or design changes that were not studied during the discussed experimental work, and to save time, cost and effort associated with model testing, it is beneficial to develop a model simulator to simulate the performance of the built ship tanker model. The developed simulator can describe the ship model dynamics and its interaction with the surrounding environment and present its main parts including its propulsion system using MATLAB/Simulink which can be used for further investigations of EEDI and SEEMP measures. The collected experimental data can also be used to validate the model simulator as will be discussed in the following section.

\section{Simulation}

A flexible time-domain quasi-steady simulator is developed in MATLAB/Simulink using building block modular approach to facilitate the modelling and simulation of the tanker ship model for further studies. This simulator is based on the mathematical modelling of the ship model main components and its interaction with the surrounding environment of wind and waves. The developed simulator is currently limited to one-Degree of Freedom (DOF) since the manoeuvrability testing were not conducted in ideal condition as discussed in the previous section and therefore, manoeuvrability experimental results are only sufficient to 
develop a simple mathematical model of the ship model motion in one DOF. Figure 7 displays an overview of the developed simulator showing its main inputs and outputs.

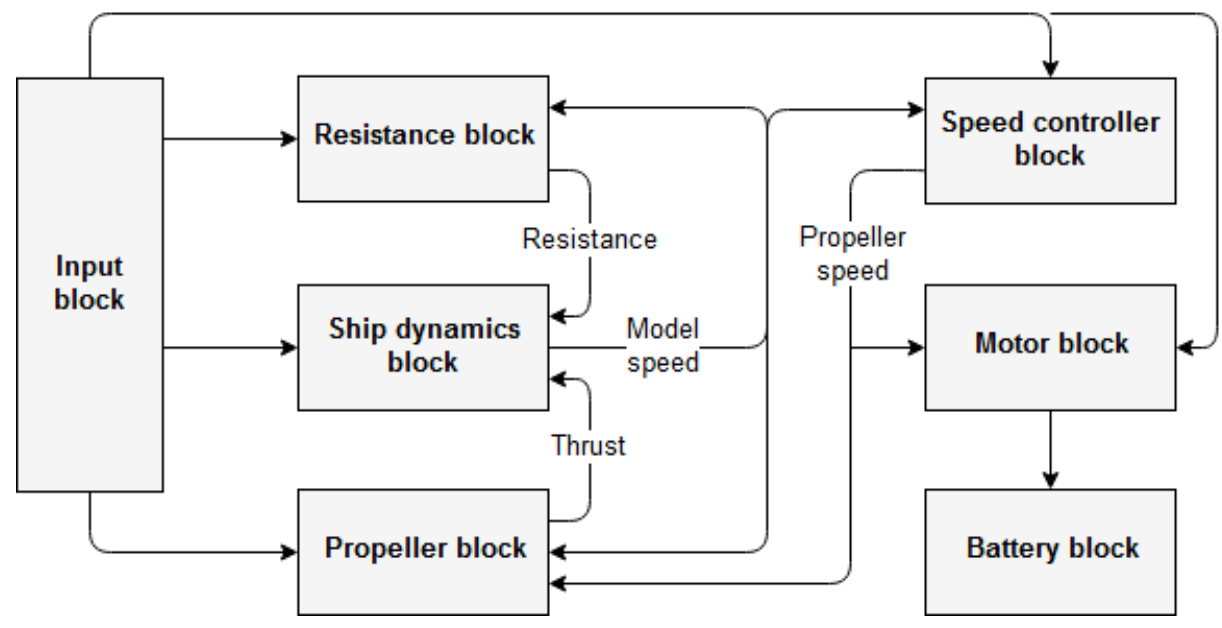

Figure 7: Representation of the developed ship model simulator

The developed simulator consists of an input block which provides the main particulars of the tanker ship model and the required model speed or the required propeller speed to the rest of the simulator blocks. The calm water resistance $(R)$ is calculated in the resistance block using a polynomial function of the model speed as suggested in (Theotokatos and Tzelepis, 2015) while added resistance due to wind and waves $(\Delta R)$ can be approximated by about $20-40 \%$ of calm water resistance (Liu et al., 2011). The propeller block is responsible for calculating the propeller torque $\left(Q_{P}\right)$ and thrust $\left(T_{P}\right)$ using Equations 6 as a function of the propeller diameter $\left(D_{p}\right)$ and speed $\left(n_{p}\right)$ and the non-dimensional thrust $\left(K_{T}\right)$ and torque coefficients $\left(K_{Q}\right)$ calculated using interpolation polynomials suitable for Wageningen B-screw series type (Molland et al. 2011).

$$
\begin{aligned}
T_{P} & =K_{T} \cdot \rho \cdot n_{p}^{2} \cdot D_{p}^{4} \\
Q_{P} & =K_{Q} \cdot \rho \cdot n_{p}^{2} \cdot D_{p}^{5}
\end{aligned}
$$

The estimated model resistance and propeller thrust are then balanced in the ship dynamics block according to Equation 7 to calculate the model longitudinal acceleration in surge direction $\left(\frac{d v}{d t}\right)$ to then estimate the model current speed as a function of the thrust deduction $(t)$, ship model mass $(M)$ and surge-surge added mass $\left(-X_{u}^{\prime}\right)$ (Theotokatos and Tzelepis, 2015).

$$
\left(M-X_{u}^{\prime}\right) \frac{d v}{d t}=T_{P}(1-t)-R-\Delta R
$$

The model current speed is then provided to the resistance and propeller blocks to perform their calculations. In case of using a predefined model speed profile as an input to the simulator, the speed controller block is activated and the required propeller speed $\left(n_{p}\right)$ is calculated backward as a function of the difference between the model predefined speed (from input block) and current speed (from ship dynamics block) using a PID controller and fed to the propeller and motor blocks. Otherwise, $n_{p}$ can be defined by the user in the input block. Next, the motor block estimates the required motor voltage $\left(U_{m o t}\right)$, current $\left(I_{m o t}\right)$ and power to run the propeller at its required speed $(n)$ as a function of the motor torque $\left(Q_{m o t}\right)$ and motor terminal resistance $\left(R_{t}\right)$ according to Equation 8 supplied by the motor manufacturer.

$$
U_{m o t} \cdot I_{m o t}=\frac{\pi}{30000} \cdot n \cdot Q_{m o t}+R_{t} \cdot I_{m o t}^{2}
$$



Figures $8 \mathrm{~b}, 8 \mathrm{c}$, and $8 \mathrm{~d}$.

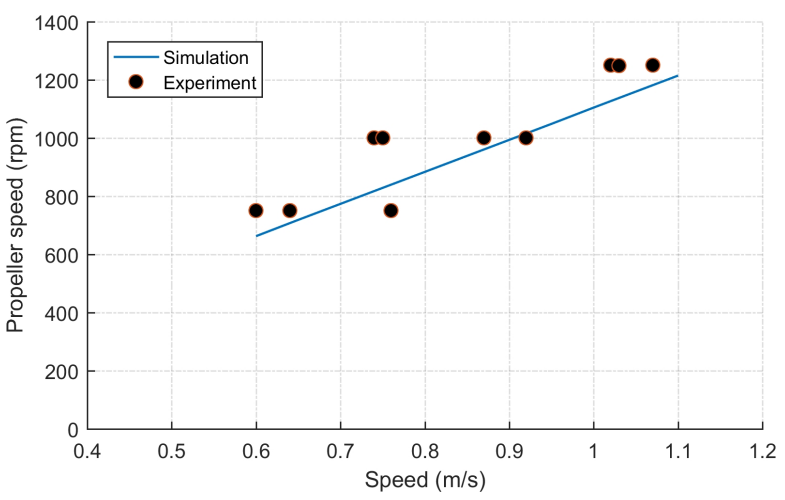

(b) Propeller speed validation

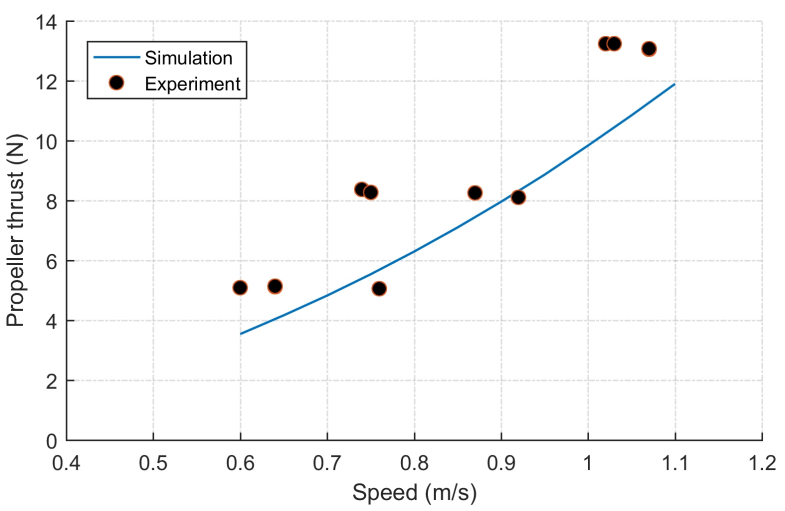

(d) Propeller thrust validation

The required motor power is then drained from the battery block whose main outputs are battery voltage, current and battery state of charge (SOC) according to the battery mathematical model presented in (Tremblay and Dessaint, 2009). In the next section, the developed simulator blocks are validated using the real experimental data of the ship model performance during towing tank and lake tests.

Simulation results of the calm water resistance block is compared to the towing tank naked hull tests experimental results of the tanker ship model using its normal bow at default trim as shown in Figure experimental data. Moreover, simulation results of the main variables of the propeller block which are frim using normal bow during straight run manoeuvres showing good agreement as shown in

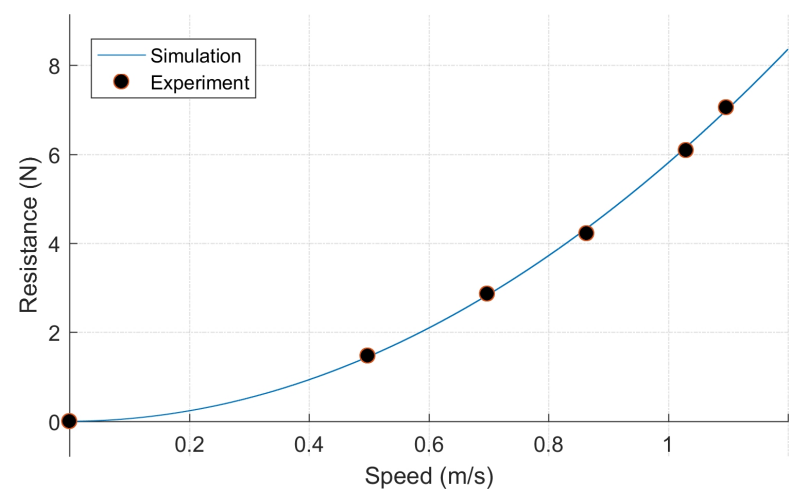

(a) Calm water resistance validation

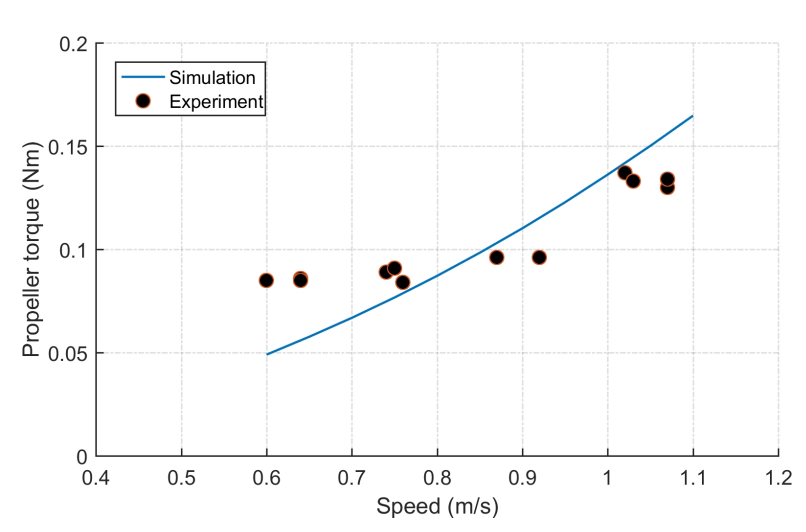

(c) Propeller torque validation

Figure 8: Validation of calm water resistance and propeller blocks 
Furthermore, the motor block is also validated using the lake testing experimental results of the ship model using its normal bow at full load condition while performing a set of manoeuvres which included straight run tests at propeller speed of 1000 and $1250 \mathrm{rpm}$, circle tests at propeller speed of $750,1000,1250$ $\mathrm{rpm}$ and rudder angle demand of $20^{\circ}, 25^{\circ}$, and $30^{\circ}$ and zig-zag tests at propeller speed of $1000 \mathrm{rpm}$ and rudder angle demand of $20^{\circ}-20^{\circ}$ as shown in Figure 9

$\overbrace{0}^{\text {Straight line }} \underbrace{500}_{\substack{\text { Straight line } \\ n_{p}=1250 \mathrm{rpm}}} \underbrace{\text { Circle test }}_{\begin{array}{c}\text { Circle test } \\ n_{p}=1000 \mathrm{rpm}\end{array}}$

Figure 9: Time line of lake experiments used for motor block validation

Figure 10a reveals that the simulated applied motor voltage is in good agreement with the experimental results. Meanwhile, There is a less than perfect agreement between simulation results and recorded readings of motor current as shown in Figure $10 \mathrm{~b}$ where the error is larger at higher motor speed or while manoeuvring. This can be justified by the fact that the frictional and electrical losses associated with the motor itself and its controller increases with increasing the motor speed. Therefore, more experimental work is required to observe the effect of motor speed on the motor losses for the sake of calibrating the built simulator. Also, the motor torque and current consumption during manoeuvrability can't be captured well by the developed one DOF simulator. Future work should therefore include manoeuvrability testing in a controlled calm water environment to accurately predict manoeuvring characteristics and power consumption of the ship model and upgrade the developed simulator.

The required motor current is then drained from the battery block which is responsible for simulating the battery behaviour and calculate its voltage and SOC. The battery block contains a lead-acid battery model already integrated in the SPS toolbox in the electric drives library of Simulink. This battery model is selected due to its ease of use, its capability of representing both dynamic and steady state behaviour of the battery and it has been well validated against experimental results as can be found in (Tremblay and Dessaint, 2009).

As can be seen from simulation results that the ship model behaviour is acceptably represented by the developed simulator. The accuracy of the simulator can be further increased by conducting more experimental work and upgrading the model hardware as described later. This simulator can then be used to test different power sources or control strategies as will be discussed later.

\section{Conclusion}

In order to comply with the tighter environmental regulations and reduce operational costs, improving ships energy efficiency has been extensively studied recently. According to the most recent IMO GHG study, $\mathrm{CO}_{2}$ ship emission could increase by between $50 \%$ and $250 \%$ by 2050 . Therefore, many measures and technologies have been suggested to increase shipping environmental and economical performance. On the other hand, it is of great concern for ship operators to select the suitable technology to improve their fleets energy efficiency because of the associated technical and economical risks. Autonomous ship models can play a major part in predicting the real potential of different EEDI and SEEMP measures through experiments due to its advantages of performing tests with higher repeatability, measurement accuracy and cost efficiency. To overcome model testing difficulties, system simulation can be also accompanied which offers an environment to analysis, tune, and optimize the system performance which helps to achieve the targeted ship energy efficiency level.

This paper introduces the main parts and control of an autonomous, self-propulsion and self-measuring free running model of an Ice Class tanker ship developed at the University of Southampton to study the 


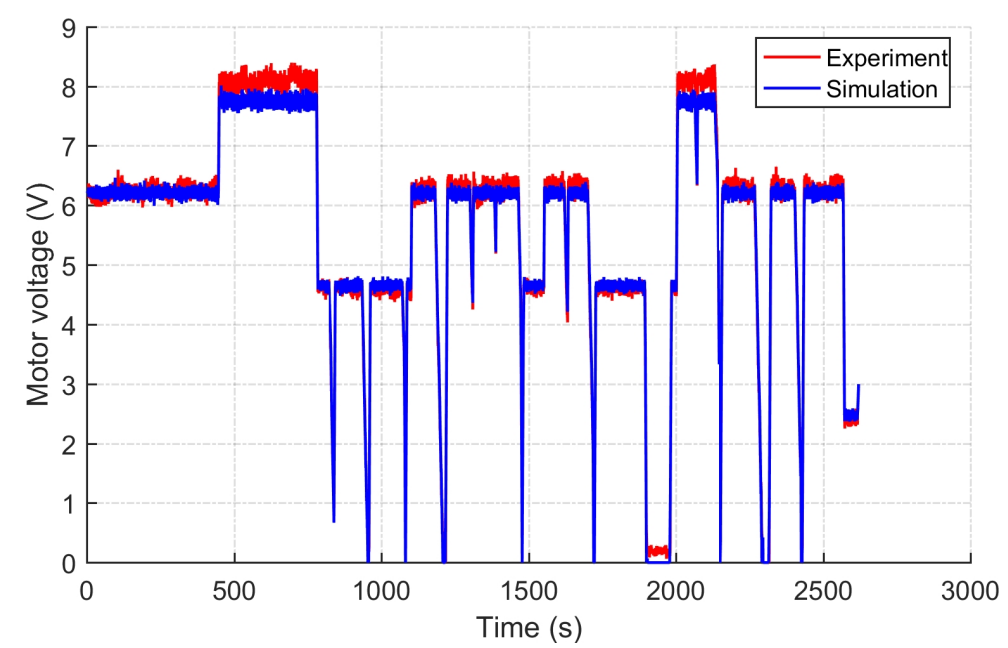

(a) Experiment vs simulation results of motor voltage readings

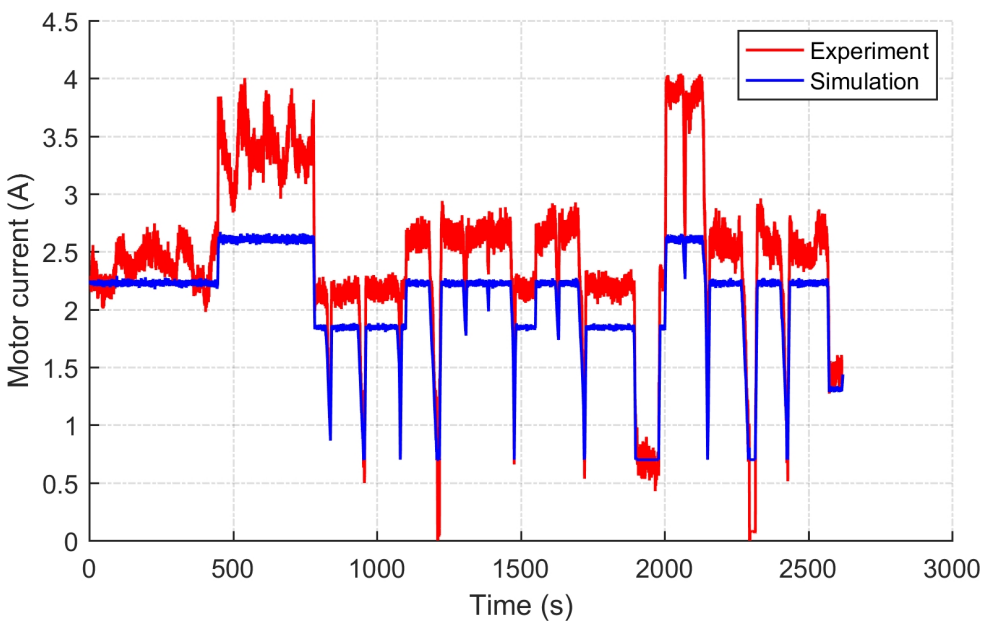

(b) Experiment vs simulation results of motor current readings

Figure 10: Validation of Motor block

effect of EEDI and SEEMP measures of using different bow designs and changing the ship operational trim. An extensive experimental campaign has been carried out using the built ship model which proved its versatility and effectiveness as a test platform and a large amount of useful data has been collected. Tests included bollard pull, shaft efficiency, naked-hull, self-propulsion tests in addition to manoeuvrability tests of straight line, circle, and zig-zag manoeuvres in different testing environment of laboratory, towing tank, and open-water lake. Towing tank naked hull test experimental results show that a small saving in power consumption of $0.6 \%$ and $2.9 \%$ can be achieved by changing the operational trim in full load and ballast load conditions respectively at the ship service speed. Also, experimental results of lake straight line testing show that using an alternative bow instead of the normal bow can result in a considerable efficiency improvement of $18.7 \%$. These experimental results demonstrate the feasibility of the targeted EEDI and SEEMP measures and more testing is planned to be done. It should, however, be noted that these experimental results are subject to measurement error and uncertainty. Therefore, a statistical analysis was performed to assess the accuracy of the ship model instruments. Also, developing the built ship model is planned.

The analysis of information provided from tests allows to obtain a flexible simulator to represent the built ship model performance in one DOF using building block modular approach in Simulink/MATLAB 
environment. This simulator has been well validated using experimental data from the model testing. Therefore, the developed simulator provides a framework for future studies to improve ship energy efficiency through simulation taking into consideration the correlation between model and ship.

\section{Further work}

Regarding the built ship model, more accurate GPS with higher sampling rate is intended to be installed for higher measurements precision. Moreover, a torque dynamometer is planned to be used after calibration for more accurate propeller torque measurements. Furthermore, a wave buoy and an anemometer to measure wave and wind conditions are recommended to be used to analyse the testing environmental conditions, decrease its associated uncertainty and enable more understanding of the future experimental data. This will also enable the validation of the developed ship model by comparing the experimental results from both the towing tank and lake testing to retain the system accuracy. Then, more testing and experimental work can be done which includes more comprehensive trim study and conducting manoeuvrability testing in calm water condition to have more accurate assessment of the model control and manoeuvrability characteristics. More ship energy efficiency measures can be tested as well such as study the effect of changing the ship operational conditions such as draft and other modifications to the vessel such as propeller type, using an aft body flow device or testing hybrid and electric power systems and its related energy management strategies and control using different power sources such as fuel cells. In addition, this investigation should include different types of ships such as bulk carriers, containers, etc. to further improve their energy efficiency. A statistical model can be also built based on the experimental data to identify changes in powering and manoeuvring characteristics.

Regarding the developed simulator, it can assist further studies of EEDI and SEEMP measures such as using alternative power sources or hybrid systems and the associated different control and energy management strategies. After modifying the built ship model as explained earlier and performing more experimental work, recalibrating the developed simulation tool for better results can be done as well as upgrading the model to 4 or 6 DOF.

\section{Acknowledgement}

The authors sincerely acknowledge the project sponsors, supervisors and team for their cooperation, sponsorship, and data provision.

\section{References}

Anderlini, E., Crossley, H., Hawkes, J., Le, H., Mozden, J., Neale, K., Thornton, B., 2013. The development of an autonomous self-propulsion vessel for powering and manoeuvring tests in an uncontrolled environment. Tech. rep., University of Southampton.

Argyros, D., Sabio, N., Raucci, C., Smith, T., 2014. Global marine fuel trends 2030. Loyd's register marine and the University college London, Tech. Rep.

Bazari, Z., Longva, T., 2011. Assessment of IMO mandated energy efficiency measures for international shipping. International Maritime Organization.

BeagleBoard, 2018. https://beagleboard.org/BeagleBoard-xM accessed: 2018-08-01.

Bennett, S., Brooks, C., Winden, B., Taunton, D., Forrester, A., Turnock, S., Hudson, D., 2014. Measurement of ship hydroelastic response using multiple wireless sensor nodes. Ocean Engineering 79, $67-80$. URL http://www.sciencedirect.com/science/article/pii/S0029801813004411

Bertram, V., 2012. Practical ship hydrodynamics, 2nd Edition. Elsevier.

Bøckmann, E., Steen, S., 2016. Model test and simulation of a ship with wavefoils. Applied Ocean Research 57, 8-18.

Cooke, R., 2013. The influence of bow shape on a model ship performance in waves. Tech. rep., University of Southampton, Individual Honours Project.

Coraddu, A., Dubbioso, G., Mauro, S., Viviani, M., 2013. Analysis of twin screw ships' asymmetric propeller behaviour by means of free running model tests. Ocean Engineering 68, 47-64.

Dunbabin, M., Grinham, A., Udy, J., 2009. An autonomous surface vehicle for water quality monitoring. In: Australasian Conference on Robotics and Automation (ACRA). Citeseer, pp. 2-4.

ITTC, 2008a. Recommended procedures and guidelines - Free running model tests $(7.5-02-06-01)$. Tech. rep. 
ITTC, 2008b. Recommended procedures and guidelines - Testing and extrapolation methods propulsion, performance propulsion test $(7.5-02-03-01.1)$. Tech. rep.

ITTC, 2017. Recommended procedures and guidelines - Predicting powering margins (7.5 - $02-03-01.5)$. Tech. rep.

Liu, S., Papanikolaou, A., Zaraphonitis, G., 2011. Prediction of added resistance of ships in waves. Ocean Engineering 38 (4), $641-650$.

Maxon, 2018. DC motor. https://www.maxonmotor.com/maxon/view/product/motor/dcmotor/re/re40/148866 accessed on: $07 / 07 / 2018$

Molland, A., Turnock, S. R., Hudson, D., September 2011. Ship resistance and propulsion: practical estimation of ship propulsive power. Cambridge University Press.

Moreira, L., Fossen, T. I., Soares, C. G., 2007. Path following control system for a tanker ship model. Ocean Engineering 34 (14-15), 2074-2085

Moreira, L., Soares, C. G., 2011. Autonomous ship model to perform manoeuvring tests. Journal of Maritime Research 8 (2), $29-46$.

Neilson, J., Tarbet, R., 1997. Propulsion system simulations: Making the right choice for the application. Naval engineers journal 109 (5), 83-98.

Perera, L., Moreira, L., Santos, F., Ferrari, V., Sutulo, S., Soares, C. G., 2012. A navigation and control platform for real-time manoeuvring of autonomous ship models. IFAC Proceedings Volumes 45 (27), 465-470.

Rehmatulla, N., Calleya, J., Smith, T., 2017. The implementation of technical energy efficiency and CO2 emission reduction measures in shipping. Ocean Engineering 139, 184-197.

Rehmatulla, N., Smith, T., 2015. Barriers to energy efficient and low carbon shipping. Ocean Engineering 110, 102-112.

Resolution MEPC.254(67), 2014. Guidelines on survey and certification of the energy efficiency design index (EEDI). Annex 5. ROS.org, 2018. http://wiki.ros.org/, accessed on: 07/07/2018.

Smith, T., O'Keeffe, E., Aldous, L., parker, S., Raucci, C., Traut, M., Corbett, J., Winebrake, J., Jalkanen, J.-P., Johansson, L., Anderson, B., Agrawal, A., Ettinger, S., Ng, S., Hanayama, S., Faber, J., Nelissen, D., Hoen, M., Lee, D., Chesworth, S., Pandey, A., Jun. 2014. Third IMO GHG study 2014. Tech. rep., International Maritime Organization (IMO), London, UK. SPS, 2018. https://www.mathworks.com/products/simpower.html, accessed: 2018-08-01.

Theotokatos, G., Tzelepis, V., 2015. A computational study on the performance and emission parameters mapping of a ship propulsion system. Proceedings of the Institution of Mechanical Engineers, Part M: Journal of Engineering for the Maritime Environment 229 (1), 58-76.

Tilman, D., Lehman, C. L., Bristow, C. E., 1998. Diversity-stability relationships: statistical inevitability or ecological consequence? The American Naturalist 151 (3), 277-282.

Tremblay, O., Dessaint, L.-A., 2009. Experimental validation of a battery dynamic model for EV applications. World Electric Vehicle Journal 3 (2), 289-298.

Zheng, J., Meng, F., Li, Y., 2018. Design and experimental testing of a free-running ship motion control platform. IEEE Access 6, 4690-4696. 